\title{
The electronic mood device: Design, construction, and application
}

\author{
JAN B. HOEKSMA, SASKIA M. SEP, FRANS C. VESTER, \\ PAUL F. C. GROOT, ROB SIJMONS, and JOHAN DE VRIES \\ Free University, Amsterdam, The Netherlands
}

\begin{abstract}
The electronic mood device (EMD) is designed to help answer questions about the variability and dynamics of emotions. It is a small, portable instrument used for repeated recording of moods and feelings. Both construction and operation of the EMD are described. The EMD can best be conceived of as an electronic mood adjective checklist. Persons using the EMD are signaled at designated (e.g., hourly) or random intervals to register their mood or feelings. Paper and pencil are not required. An application is given. It shows how feelings vary within and between persons and during the day. It is concluded that the EMD offers several advantages over paper-and-pencil instruments. Retrospective use is impossible. Timing and registration are accurate. Data handling is fast. Potential future applications are suggested.
\end{abstract}

There appears to be a growing interest in temporal and dynamical aspects of feelings and emotions (Magai \& McFadden, 1995). Frijda, Mesquita, Sonnemans, and van Goozen (1991) studied the duration of emotions, sentiments, and passions. Frijda et al. used retrospective selfreports. Malatesta and Culver (1991) examined continuous and spike-like patterns of moods and emotions. They collected diary data to identify emotions and moods. More recently, Nesselroade and Featherman (1997) stressed the importance of research into the variability of behavior and affect. They contended that the variability of behaviors and emotions deserves more attention than their stability. Given this interest, there is a need for user- and researcher-friendly instruments that allow for frequent sampling of feelings and emotions. The present study was specifically aimed at developing and testing such an instrument.

Within the field of psychopathology, the so-called experience sampling method (ESM) is well established (de Vries, 1992). The general purpose of the ESM is to study the subjective experience of persons interacting in their natural environments (Csikszentmihalyi \& Larson, 1987). The method is used to reveal regularities in a person's stream of consciousness, actions, and feelings. It was first used by Brandstätter (1977) and Csikszentmihalyi, Larson, and Prescott (1977).

ESM is based on time sampling (Brandstätter, 1991). Research participants are signaled by means of electronic beepers to respond at regular (e.g., hourly) intervals (Pervin, 1985). When prompted by the signal, the

We thank Marco Benard for drawing the electronic mood device and Peter de Jong for his advice in an early phase of the project. Correspondence should be addressed to J. B. Hoeksma, Vrije Universiteit, Department of Developmental Psychology, van der Boechorststraat I, 1081BT Amsterdam, The Netherlands (e-mail: jb.hoeksma@psy.vu.nl).

- Accepted by previous editor, Robert W. Proctor participant writes down information about his/her momentary situation, thoughts, and feelings (Csikszentmihalyi \& Larson, 1987). The responses typically range from simple ratings of feelings (Brandstätter, 1991) to full descriptions of feelings, thoughts, and circumstances (Hormuth, 1986). In general, responses are recorded by means of paper and pencil. Barr-Taylor, Fried, and Kenardy (1990) and Totterdell and Folkard (1992) were the first to use programmable hand-held computers for administering the ESM.

Our work resulted in what we designated the electronic mood device (EMD). The EMD is a portable instrument designed to register the intensity of a person's feelings and emotions at specific or random points in time during 1 or several days, by means of self-report. One of its main features is that the signaling and registration parts are integrated in the same instrument. It does not require paper and pencil. The EMD should provide a research tool to investigate the dynamic aspects of feelings and emotions. It should be helpful in answering questions such as, "What is the duration of emotions? How do feelings vary during the day? Are some moods more variable than others?" In the next section, we turn to a description of the EMD, followed by an application that shows how such questions can be answered.

\section{Design and Construction}

In designing the EMD, we had several requirements in mind. The instrument should be user and researcher friendly. That is, the user should be able to use the instrument with minimal instruction and effort. The instrument should be portable and appealing to the user. At the same time, the researcher should have maximum flexibility to adjust the instrument to his/her specific needs. $\mathrm{He} / \mathrm{she}$ should be able to freely choose the emotions and feeling to be studied. The sampling interval should be adjustable to different fixed or random intervals. Finally, the instrument should allow for automatic 
data handling because experience sampling generally results in large individual data sets.

The instrument can be conceived of as an electronic analogue of a paper-and-pencil mood adjective scale containing some 10 items concerning the person's moods and emotions. Figure 1 shows the EMD. It consists of a box measuring $3 \times 7 \times 11 \mathrm{~cm}$ (height $\times$ width $\times$ diameter). The front panel of the box contains an eight-character dot display. It is used to display words that pertain to feelings and emotions, for instance, happy, angry, aroused, or sad. Nine tiny red bulbs (light-emitting electrodes) are affixed below the display. They correspond to 9 virtual points on a Likert scale. On each side of the display there is a small push button. The push buttons are used by the participant to adjust his/her response according to his/her feelings.

The heart of the EMD consists of a microprocessor and memory of $128 \mathrm{~K}$ RAM. It is powered by a $9-\mathrm{V}$ powerpack. The electronic circuit functions on $5 \mathrm{~V}$. So-called static RAM and a switched-down regulator are used to reduce power consumption. With a long-life powerpack, the EMD can be used for over a week. Part of the technology employed was used earlier in an ambulatory monitoring system for cardiography (Willemsen, de Geus, Klaver, van Doornen, \& Carrol, 1996).

The EMD is operated as follows. Before the EMD is handed over to the participant, it is programmed using dedicated software. First, the researcher enters the emotion words to be displayed. A common number of words is 10 . The words can be displayed or presented to the participant in fixed or random order. Second, the signaling interval is chosen. It can range from several minutes to several hours. Finally, the option of random or fixed intervals between signaling is considered. In the case of random signaling, a fixed interval (e.g., an hour) plus or minus a random interval (ranging from 1 to several minutes) is used. The EMD has an internal clock that adjusts itself to the internal clock of the PC, used for programming the instrument.

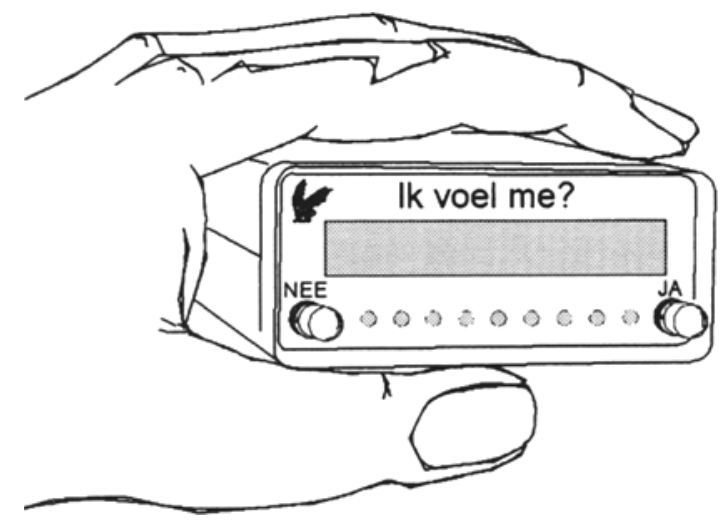

Figure 1. The Electronic Mood Device. The Dutch sentence $I k$ voel me means "I feel." Ja means "yes," and nee means "no."
The participant switches the EMD on by simultaneously pushing the left and right buttons on the display. The EMD answers by displaying "Start Y/N." The participant responds by pushing the right button, indicating "yes." Then the first emotion word is presented (e.g., angry). The bulb in the center of the nine tiny red bulbs below the display lights up. The participant expresses his/her feeling by adjusting the light to the right or left. Each push on the right button moves the light one step to the right, indicating that the participant's feeling agrees with the feeling on the display. Each push on the left button moves the light to the left indicating that his/her feeling disagrees with the feeling displayed. When the person stops adjusting his/her response (i.e., moving the lights), the next emotion word is presented within seconds. Internally, the EMD registers and saves the time, the emotion word presented, and responses, using numbers ranging from 1 to 9 .

After the final emotion word is presented, the EMD turns itself down. Then, after the preselected interval, the EMD gives a signal. When the participant hears the beep, he/she turns the instrument on by pushing both buttons again. The first emotion word is presented, followed by a response from the participant, and so on. By the end the day, the person turns off the EMD by pushing both buttons simultaneously. The instrument responds with "Stop $\mathrm{Y} / \mathrm{N}$ " on the display. By pushing the right button (Yes), the participant turns off the EMD. The next morning the same steps are repeated. The participant turns the EMD on by pushing both buttons, and so on.

Once the registration is finished, the EMD is given to the researcher. Next, the EMD is connected to the RS232 port of the personal computer to download the data. The downloaded file contains general information including identification of the participant, the emotion words, and data records. Each record contains the time of registration and the responses (1-9) to the emotion words. The original random order of the words presented is preserved in the data file.

\section{Application of the EMD}

The EMD is a research tool designed to investigate the dynamic aspects of feelings and emotions. To illustrate its use, a small research study was performed. It was guided by the question: How do moods vary within and across individuals during the day?

\section{METHOD}

Participants were 29 subjects ( 15 female, 14 male). The mean age was 41.6 years $(S D=18.2)$. They received both written and oral instruction on how to operate the EMD. The 1st day, participants became accustomed to using the device. Registrations started after participants arose in the morning and ended at bedtime. The sampling rate was set at a random hourly interval (up to a maximum of $\pm 5 \mathrm{~min}$ ). Each hour, the following words were presented in random order: cheerful, bright, sad, down, lucid, calm, energetic, and fit. The total number of data records was 422 , corresponding to 14.6 records per person. 
Table 1

Parameter Estimates (and Standard Errors) of the Multilevel Models for Eight Feelings

\begin{tabular}{|c|c|c|c|c|c|c|c|c|c|c|c|c|c|c|c|c|}
\hline & \multicolumn{2}{|c|}{ Sad } & \multicolumn{2}{|c|}{ Down } & \multicolumn{2}{|c|}{ Cheerful } & \multicolumn{2}{|c|}{ Bright } & \multicolumn{2}{|c|}{ Lucid } & \multicolumn{2}{|c|}{ Calm } & \multicolumn{2}{|c|}{ Energetic } & \multicolumn{2}{|l|}{ Fit } \\
\hline & $\mathrm{PE}$ & $S E$ & PE & $S E$ & PE & $S E$ & $\mathrm{PE}$ & $S E$ & PE & $S E$ & $\mathrm{PE}$ & $S E$ & $\mathrm{PE}$ & $S E$ & PE & $S E$ \\
\hline \multicolumn{17}{|l|}{ Fixed } \\
\hline$\beta_{0}$ & 1.71 & .13 & 1.83 & .13 & 7.11 & .18 & 7.38 & .16 & 7.50 & .14 & 7.09 & .027 & 7.20 & .20 & 7.07 & .17 \\
\hline$\beta_{1}$ & .0040 & .015 & - & - & .020 & .021 & .016 & .020 & .043 & .023 & -.053 & .027 & .011 & .027 & 0.013 & .023 \\
\hline$\beta_{2}$ & - & - & - & - & -.0046 & .0022 & -.020 & .0061 & -.012 & .0025 & .0062 & .0031 & -.023 & .0062 & -.011 & .0025 \\
\hline $\begin{array}{c}\beta_{3} \\
\text { evel } 2\end{array}$ & - & - & 一 & - & - & - & .0014 & .00055 & - & - & - & - & .0014 & .00059 & - & - \\
\hline$\sigma_{u 0}^{2}$ & .46 & .13 & .4 & 12 & & \multicolumn{4}{|c|}{ evel 2} & & 1. & & & .2 & & .22 \\
\hline$\sigma_{u \theta, u l}$ & -.017 & .011 & - & - & -.012 & .014 & - & - & .014 & .013 & -.020 & .022 & -.040 & .023 & -.0046 & .014 \\
\hline$\sigma_{u l}^{2}$ & .0046 & .0018 & - & - & .0034 & .0016 & - & - & .0051 & .0022 & .0036 & .0023 & .0096 & .0035 & .0035 & .0018 \\
\hline \multicolumn{17}{|l|}{ Level 1} \\
\hline$\sigma_{e \theta}^{2}$ & .48 & .037 & .85 & .061 & .79 & .058 & .98 & .070 & .91 & .067 & 1.47 & .11 & .77 & .084 & .96 & .071 \\
\hline$\sigma_{e(0, e l}$ & .032 & .0048 & - & - & - & - & - & - & - & - & - & - & -.018 & .015 & - & - \\
\hline$\sigma_{e l}^{2}$ & - & - & - & - & - & - & - & - & - & - & - & - & .0086 & .0040 & - & - \\
\hline
\end{tabular}

Note-Time centered at $12 \mathrm{~h}$.

\section{Data Analysis}

The data were analyzed by means of hierarchical linear model (Bryk \& Raudenbush, 1992). This statistical technique is also known as multilevel analysis (Goldstein, 1995). The purpose of the analysis was to show (1) how feelings change during the day, (2) how they vary between individuals, and (3) how they fluctuate within individuals. Bryk and Raudenbush (1987) and Hoeksma and Koomen (1992) have shown that the model is well suited for that purpose.

A separate analysis was performed for each affect. In the longitudinal multilevel model, the observed response $y$ at occasion $i$ of person $j$ is written as a polynomial function of time, $x$. The model is

$$
y_{i j}=\sum_{h} \beta_{h} x_{i j}^{h}+\sum_{h} u_{h j} x_{i j}^{h}+\sum_{h} e_{h i j} x_{i j}^{h} \text {. }
$$

Index $h$ designates the order of the polynomials $(h=0,1, \ldots, s)$. The parameters $\beta_{h}$ are coefficients of the average polynomial curve. Parameter $\beta_{0}$ is the intercept, $\beta_{1}$ the linear coefficient, and so on. Together they are labeled the fixed part of the model. Fixed parameters are included in the model when they exceed twice their standard error. The $u_{h j}$ refer to random individual differences with $E\left(u_{h j}\right)=0, \operatorname{Var}\left(u_{h j}\right)=\sigma_{u h}^{2}$, and $\operatorname{Cov}\left(u_{h j}, u_{h^{\prime} j}\right)=\sigma_{u h, h^{\prime}}$. Parameters $\sigma_{u b}^{2}$ and $\sigma_{u l}^{2}$ reveal how the intercept and linear coefficients vary across individuals. They are labeled the Level 2 parameters. The $e_{h i j}$ refer to the residuals (within persons) with $E\left(e_{h i j}\right)=0$ and $\operatorname{Var}\left(e_{h i j}\right)=\sigma_{e h}^{2}$, and $\operatorname{Cov}\left(e_{h i j}, e_{h^{\prime} i j}\right)=\sigma_{e h, e h^{\prime}}$. They are labeled the Level I parameters. In the present case, the residual variance refers to fluctuations within persons. Significance of the variance components is tested by comparing the likelihood of the model with and without the specific component involved (Goldstein, 1995).

\section{RESULTS}

A hierarchical linear model was fitted for each affect. Table 1 shows the parameter estimates of the resulting models. The fixed parameters $\left(\beta_{1}-\beta_{4}\right)$ are used to depict the mean level of each feeling (Figure 2). The Level 2 parameters $\left(\sigma_{u}^{2}\right.$, etc. $)$ are used to delineate the betweenperson variance. Finally the Level 1 parameters $\left(\sigma_{e}^{2}\right.$, etc.) are used to delineate the within-person fluctuations. Together, the Level 2 and Level 1 variance produce the total variance (Figure 2).

For the two negative feelings sad and down, a (near) constant mean level was observed. Figure 2 shows how the variability of sad increases during the day. The between-person variability was somewhat larger in the morning and evening. The within-person fluctuations of sad were most obvious in the afternoon. The variability of feeling down was constant during the day. Figure 2 also shows that the between-person variance of down accounts for a relatively small part of the total variance.

The mean curves of the six positive affects follow curvilinear patterns. For cheerful, lucid, energetic, and fit maximums were observed around noon. For calm, a minimum was observed at noon, whereas for bright, no clear extremum was found. For all positive feelings except bright, a complex pattern of between-person variation (Level 2 variance) was found. Figure 2 shows that the most tangible differences were observed for lucid and energetic. Individual differences in feeling lucid increased during the day. For energetic, the individual differences were obvious both early in the morning and late in the afternoon. Except for energetic, the fluctuations of the positive feelings did not depend on the time of the day (only $\sigma_{e}^{2}$ is included in the model). The complex Level 1 variance of energetic depicted in Figure 2 points to large fluctuations early in the morning and late in the afternoon.

\section{DISCUSSION}

The EMD is a tool to register the intensity of a person's feelings during a certain period of time. This period may range from several hours to several days. The application described is based on a period of 1 day. It shows how repeated measurements collected by means of the EMD can be used to answer questions regarding change and variability of emotions.

The EMD offers at least three advantages relative to traditional paper-and-pencil instruments used to collect mood data. First, persons using the EMD cannot look back at their previous answers. As a result, the participant's freedom to create a consistent picture of his/her moods is reduced. Second, the EMD saves the current 

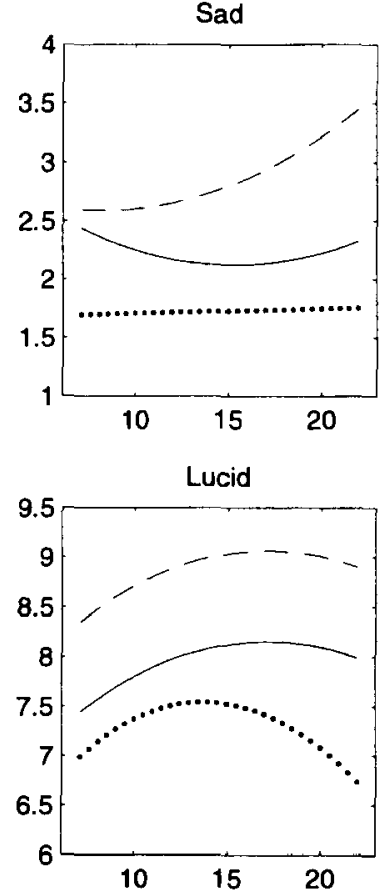
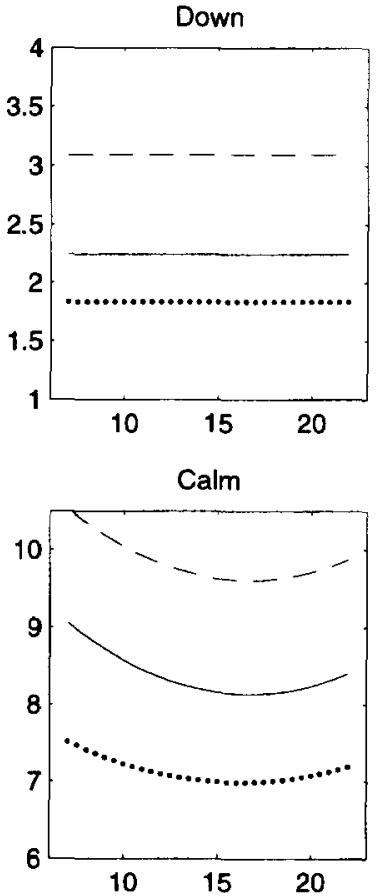
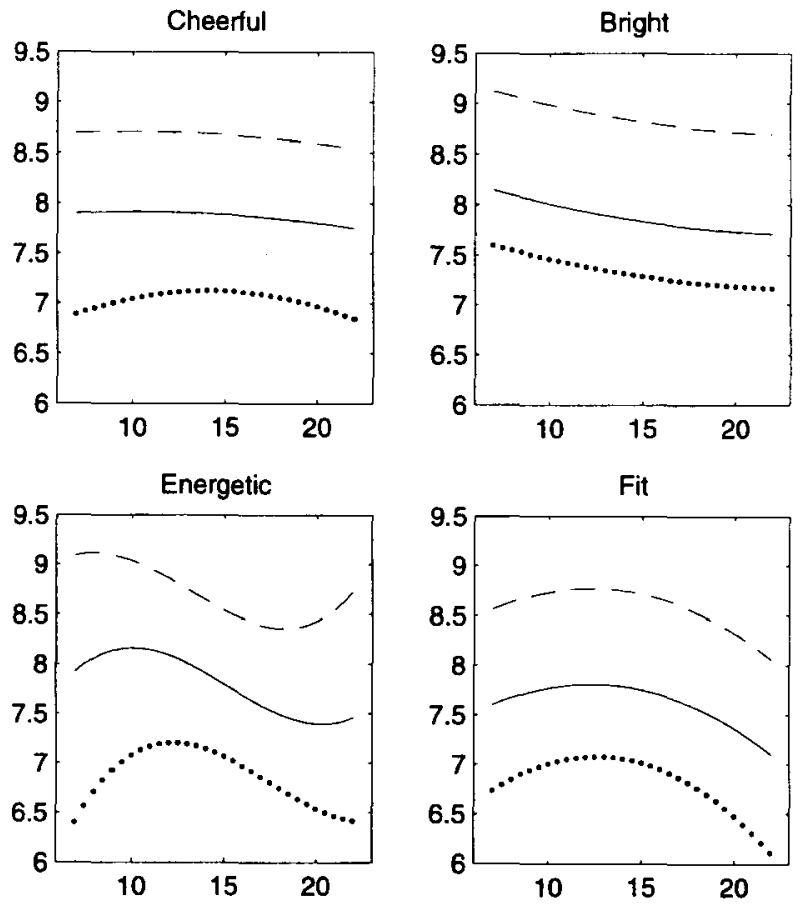

Figure 2. Change and variability of eight moods. Average change (dotted line), between-person variability (distance between solid and dotted lines), and within-person variability (distance between solid and dashed lines). Horizontal axis: time in hours. Vertical axis: scale points.

time accurately. Thus, participants using the EMD cannot enter their feelings in retrospect. Third, the device relieves the burden of data entry that normally accompanies collection of diary data. Transfer of data from device to computer can be done very quickly.

Data analysis by means of the multilevel model or hierarchical linear model is not part of the device. Nevertheless, availability of the model enhances its usefulness and applicability. The present results illustrate how the model conveniently partitions the total variance into mean changes, differences between persons, and mood fluctuations within persons. An important benefit of the model is that it does not require repeated measurements at fixed occasions, and it allows for missing values without deletion of full records (Goldstein 1995; Hoeksma \& Koomen, 1992). Thus, the model appears to be well suited to answer questions involving the dynamics of moods.

There are many potential applications of the EMD, both in clinically and theoretically oriented research. The EMD could be used to evaluate therapeutic interventions and to help patients provide feedback on their feelings. Even diagnostic usage could be expected. More theoretically oriented research would be directed at questions the EMD is really intended for-to study the variability and dynamics of emotions.

\section{REFERENCES}

BARR-TAYLOR, C., Fried, L., \& Kenardy, J. (1990). The use of a real time computer diary for data acquisition and processing. Behavior Research Therapy, 28, 93-97
BRANDSTÄTTER, H. (1977). Wohlbefinden and Unbehagen: Entwurf eines Verfahrens zur Messing situationsabhängiger Stimmungen [Well-being and uneasiness: The design of an instrument to measure situationdependent moods]. In W. H. Tack (Ed.), Bericht über den 30. Kongress der DGPs in Regensburg 1976 (pp. 60-62). Göttingen: Hogrefe.

BRANDSTÄTTER, H. (1991). Emotions in everyday life situations. In F. Strack, M. Argyle, \& N. Schwarz (Eds.), Subjective well-being (pp. 173-192). Oxford, U.K.: Pergamon.

BRYK, A. S., \& RAUdENBUSH, S. W. (1987). Application of hierarchical linear models to assessing change. Psychological Bulletin, 101, 147-158.

Bryk, A. S., \& Raudenbush, S. W. (1992). Hierarchical linear models. Newbury Park, CA: Sage.

CsiksZentmiHALYI, M., \& LARSON, R. (1987). Validity and reliability of the experience-sampling method. Journal of Nervous \& Mental Disease, 175, 526-536.

Csikszentmihalyi, M., Larson, R., \& Prescott, S. (1977). The ecology of adolescent activity and experience. Journal of Youth $\&$ Adolescence, 6, 281-294.

DE VRIES, M. W. (1992). The experience sampling method. Cambridge: Cambridge University Press.

Frijda, N. H., Mesquita, B., Sonnemans, J., \& van Goozen, S. (1991). The duration of affective phenomena, or emotions, sentiments, and passions. In K. T. Strongman (Ed.), International review of studies on emotion (Vol. 1, pp. 187-225). Chichester, U.K.: Wiley.

GoldSTEIN, H. (1995). Multilevel statistical models. London: Arnold. Hoeksma, J. B., \& KoOMEN, H. M. Y. (1992). Multilevel models in developmental psychological research: Rationales and applications. Early Development \& Parenting, 1, 157-167.

HoRmUTH, S. E. (1986). The sampling of experiences in situ. Journal of Personality, 54, 262-293.

MaGaI, C.. \& MCFadden, S. H. (1995). The role of emotions in social and personality development: History, theory, and research. New York: Plenum

Malatesta, C.Z., \& Culver, L.C. (1991). Identification of emotions, moods and personality via diary data. In K. T. Strongman (Ed.), International review of studies on emotion (Vol. 1, pp. 163-186). Chichester, U.K.: Wiley. 
Nesselroade, J. R., \& Featherman, D. L. (1997). Establishing a reference frame against which to chart age-related change. In M. A. Hardy (Ed.), Studying aging and social change: Conceptual and methodological issues (pp. 191-205). Thousand Oaks, CA: Sage. Pervin, L. A. (1985). Personality: Current controversies, issues, and directions. Annual Review of Psychology, 36, 83-114.

TotTerdell, P., \& FolkarD, S. (1992). In situ repeated measures of affect and cognitive performance facilitated by use of a hand-held computer. Behavior Research Methods, Instruments, \& Computers, 24, 545-553.

Willemsen, G. H. M., de Geus, E. J. C., Klaver, C. H. A. M., van Doornen, L. J. P., \& Carrol, D. (1996). Ambulatory monitoring of the impedance cardiogram. Psychophysiology, 33, 184-193.

(Manuscript received August 3, 1998; revision accepted for publication October 5, 1999.) 